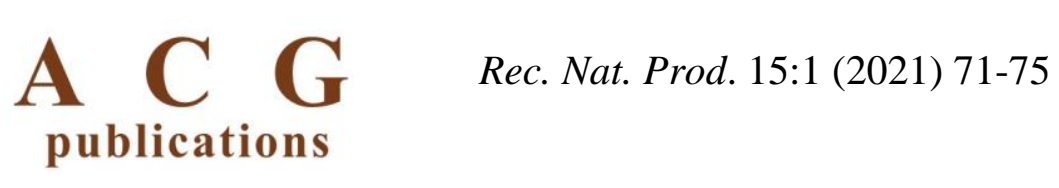

records of natural products

\title{
Cytotoxic Activity and Phytochemical Constituents of Macrosolen bidoupensis Tangane \& V.S. Dang
}

\section{Kieu Hung Le $\odot^{1,2}$, Tran Canh Nguyen $\oplus^{1}$, The Anh Nguyen $\oplus^{3}$, Nu Dan Phuong Nguyen $\oplus^{4}$, Thi Hong Tuoi Do $\oplus^{5}$, Le Thanh Tuyen Nguyen $\oplus^{6}$, Van Son Dang $\oplus^{7}$, Trong Duc Tran $\odot^{8}$, Nhat Minh Phan $\oplus^{9}$, Trong Dat Bui ${ }^{9}$, Dinh Tri Mai ${ }^{1,9}$ and Tan Phat Nguyen $\oplus^{* 1,9}$}

\author{
${ }^{1}$ Graduate University of Science and Technology, Viet Nam Academy of Science and \\ Technology, 18 Hoang Quoc Viet, Cau Giay, Hanoi, Viet Nam \\ ${ }^{2}$ Le Quy Don High School for the Gifted, Ba Ria-Vung Tau Province, Viet Nam \\ ${ }^{3}$ Bui Thi Xuan High School, Ho Chi Minh City, Viet Nam \\ ${ }^{4}$ Tran Phu High School, Binh Phuoc Province, Viet Nam \\ ${ }^{5}$ Department of Pharmacology, Faculty of Pharmacy, University of Medicine and Pharmacy \\ at Ho Chi Minh city, Viet Nam \\ ${ }^{6}$ Saigon Pharmaceutical Sciences \&Technologies Center, University of Medicine and \\ Pharmacy at Ho Chi Minh city, Viet Nam \\ ${ }^{7}$ Institute of Tropical Biology, Vietnam Academy of Science and Technology, 85 Tran Quoc \\ Toan, Ho Chi Minh city, Viet Nam \\ ${ }^{8}$ GeneCology Research Centre, University of the Sunshine Coast, 90 Sippy Downs Drive, \\ Sippy Downs, Queensland 4556, Australia \\ ${ }^{9}$ Institute of Chemical Technology, Vietnam Academy of Science and Technology, 01 Mac \\ Dinh Chi, Ho Chi Minh City, Viet Nam
}

(Received February 08, 2020; Revised September 01, 2020; Accepted September 02, 2020)

\begin{abstract}
Phytochemical investigations of the whole plants of Macrosolen bidoupensis Tangane \& V.S. Dang, a new species discovered in Viet Nam were conducted and led to the purification of ten compounds, comprising three lupane-type (1-3), three friedelane-type (4-6), and one glutinane-type (7) triterpenoids and three cholestane-type steroids (8-10) using various chromatographic methods. Their structures were characterized by HR-ESI-MS, NMR experiments and comparison with previous literature. Compounds 1, 3 and $\mathbf{5}$ expressed moderate cytotoxicity against two tested cell lines - MDA-MB-231 and RD ( IC $_{50}$ ranged from 34.19 to 74.25 $\mu \mathrm{M}$ ), whereas compounds 4 and 6 exhibited selective cytotoxic activity ( $\mathrm{IC}_{50}$ ranged from 29.07 to $45.20 \mu \mathrm{M}$ ).
\end{abstract}

Keywords: Macrosolen bidoupensis; Loranthaceae; cytotoxic activity; triterpenoid; steroid. (C) 2020 ACG Publications. All rights reserved.

\footnotetext{
* Corresponding author: E- Mail: ntphat@ict.vast.vn Phone +84 91936-0751.
} 


\section{Plant Source}

The whole plants of Macrosolen bidoupesis were collected in Bidoup Nui Ba National Park, Lam Dong Province, Viet Nam in December 2018 and identified by Dr. Van Son Dang, Institute of Tropical Biology, Vietnam Academy of Science and Technology. A voucher specimen (No.VH/PHAT-MB1218) was deposited in Bioactive Compounds Laboratory, Institute of Chemical Technology, Vietnam Academy of Science and Technology.

\section{Previous Studies}

Macrosolen bidoupensis is a new species that was discovered in Bidoup, Nui Ba National Park, Lam Dong Province, Viet Nam in 2017 [1]. There is no report on the phytochemical components and biological activities of this species.

\section{Present Study}

The whole-plant powder of M. bidoupensis ( $8 \mathrm{~kg}$ ) was extracted with $96 \% \mathrm{EtOH}(3 \times 30 \mathrm{~L})$ at room temperature. After filtering the residue, the solvents were removed under low pressure and the crude extract was obtained. The crude extract $(1000 \mathrm{~g})$ was applied to liquid-liquid extraction procedures and successively partitioned into $n$-hexane, ethyl acetate (EtOAc), and aqueous partition. The $n$-hexane extract ( $98 \mathrm{~g}$ ) was subjected to silica gel column chromatography with mobile phase $n$ hexane-EtOAc (100-0 to 0-100, v/v) to yield five fractions (MBH.I-MBH.V). As the same manner, the EtOAc extract $(33 \mathrm{~g})$ was separated on silica gel column chromatography with solvent $n$-hexaneEtOAc gradient to obtain five fractions (MBE.I-MBE.V).

MTT assay was performed using the MTT test, as previously described [2]. For the cytotoxicity, the percentage of control $(\%)$ was calculated $=\mathrm{OD}_{570 \text { sample }} / \mathrm{OD}_{570 \text { control }}$ x $100 \%$ measured at the different concentrations $(12.5,25.0,50.0$ and $100.0 \mu \mathrm{g} / \mathrm{mL})$ by MTT assay.

The cytotoxic effects of all fractions from the $n$-hexane and ethyl acetate extracts of Macrosolen bidoupensis whole plants were evaluated against two human cancer cell lines (MDA-MB231 and RD) by MTT assay (Table 1). All of the fractions except fraction MBE.V displayed cytotoxicity ( $\mathrm{IC}_{50}$ ranged from $4.52 \pm 0.33$ to $68.66 \pm 1.81 \mu \mathrm{g} / \mathrm{mL}$ ). Among them, fractions MBH.III and MBE.II revealed strong cytotoxic properties towards breast cancer cell lines (MDA-MB-231) with $\mathrm{IC}_{50}$ value of $4.52 \pm 0.33$ and $4.75 \pm 0.42 \mu \mathrm{g} / \mathrm{mL}$, respectively, while fractions MBH.IV and MBE.III exhibited significant cytotoxic activity against Rhabdomyosarcoma cell lines (RD) with $\mathrm{IC}_{50}$ value of $20.37 \pm 1.01$ and $19.78 \pm 3.12 \mu \mathrm{g} / \mathrm{mL}$, respectively. Therefore, all positive fractions were further investigated for their phytochemical constituents.

Fraction MBH.I (45 g) was eluted with solvent $n$-hexane-EtOAc gradient (100-0 to $0-100$, v/v) on silica gel column to give six sub-fractions (MBH.I.1-MBH.I.6). Subfraction MBH.I.2 (7 g) was chromatographed with solvent system $n$-hexane-EtOAc $(99: 1, \mathrm{v} / \mathrm{v})$ to obtain compounds $4(900 \mathrm{mg})$ and 7 (5 mg). Fraction MBH.II (39 g) was eluted with solvent $n$-hexane-EtOAc gradient (100-0 to 8020, v/v) on silica gel column to give six sub-fractions (MBH.II.1-MBH.II.6). Subfraction MBH.II.2 $(10 \mathrm{~g})$ was chromatographed with solvent system $n$-hexane-EtOAc $(99: 1$ to $95: 5, \mathrm{v} / \mathrm{v})$ to obtain compounds 1 (1000 mg), 2 (6 mg), 8 (4 mg), 9 and $\mathbf{1 0}(50 \mathrm{mg})$. Fraction MBH.III (3 g) was separated using solvent $n$-hexane-EtOAc $(98-2$, v/v) to give $\mathbf{1}(50 \mathrm{mg})$ and $\mathbf{3}(6 \mathrm{mg})$. Fraction MBE.II $(8 \mathrm{~g})$ was rechromatographed on silica gel with solvent $n$-hexane-EtOAc gradient (99-1 to 80-20, v/v) to yield $\mathbf{5}$ $(20 \mathrm{mg})$ and $\mathbf{6}(7 \mathrm{mg})$.

The HR-ESI-MS and NMR data of the three others were consistent with those reports in the literature for lupeol (1) [3,4], betulin (2) [5], betulinic acid (3) [6], friedelin (4), $3 \alpha$-friedelanol (5), $3 \beta$ hydroxyfriedelane-28-oic acid (6) [7], $3 \beta$-hydroxyglutin-5-ene (7) [8], $3 \beta$-cholesterol acetate (8) [9], and a mixtures of $24 \beta$-ethylcholesterol (9) and $24 \beta$-ethylcholesta-5,22-diene-3 $\beta$-ol (10) [10] (Figure 1). All of those compounds, except $\mathbf{1}$, were reported from the genus Macrosolen for the first time. 
Table 1. Cytotoxic activity of all fractions

\begin{tabular}{ccc}
\hline Cell line & Fraction & IC $_{\mathbf{5 0}}(\mu \mathrm{g} / \mathrm{mL})$ \\
\hline & H.I & - \\
H.II & $31.55 \pm 1.51$ \\
H.II & $4.52 \pm 0.33$ \\
H.IV & $15.05 \pm 0.99$ \\
MDA-MB-231 & H.V & $68.66 \pm 1.81$ \\
E.I & $27.24 \pm 1.00$ \\
& E.II & $4.75 \pm 0.42$ \\
E.III & $18.39 \pm 2.15$ \\
E.IV & $42.96 \pm 1.46$ \\
E.V & $>100.00$ \\
& Paclitaxel & $8.38 \pm 0.75(\mu \mathrm{M})$ \\
\hline H.I & - \\
H.II & $32.30 \pm 0.34$ \\
H.III & $48.40 \pm 3.05$ \\
RD & H.IV & $20.37 \pm 1.01$ \\
& H.V & $41.36 \pm 0.62$ \\
& E.I & $41.94 \pm 3.56$ \\
& E.II & $30.12 \pm 2.96$ \\
E.III & $19.78 \pm 3.12$ \\
& E.IV & $50.43 \pm 1.11$ \\
E.V & $>100.00$ \\
& Paclitaxel & $5.73 \pm 0.27(\mu \mathrm{M})$ \\
\hline
\end{tabular}

ainsoluble

The cytotoxic activities of five triterpenoids $(\mathbf{1}, \mathbf{3 - 6})$ were examined against two human cancer cell lines (MDA-MB-231 and RD) by MTT assay (Table 2) and compounds $\mathbf{1}, \mathbf{3}$ and $\mathbf{5}$ showed meaningful cytotoxicity against all tested cell lines $\left(\mathrm{IC}_{50}\right.$ ranged from $34.19 \pm 0.53$ to $74.25 \pm 0.46$ $\mu \mathrm{M}$ ), whereas, compound 4 displayed selective cytotoxic property against MDA-MB-231 cells $\left(\mathrm{IC}_{50}\right.$ value of $45.20 \pm 1.37 \mu \mathrm{M})$ and compound 6 exhibited cytotoxic effect against RD cells $\left(\mathrm{IC}_{50}\right.$ value of $29.07 \pm 3.47 \mu \mathrm{M}$ ). According to those results, we conlclude that the friedelane and lupane triterpenoids evinced as the essential components that accounted for the cytotoxic effect of $M$. bidoupensis against two tested human cancer cell lines. However, further clinical examinations are required to determine the molecular mechanisms of cytotoxicity as well as qualitative and quantitative identification of main biological triterpenoid markers ( $\mathbf{1}$ and $\mathbf{4})$ from this species.

Table 2. Cytotoxic activity of five triterpenoids $\mathbf{1 , 4 - 6}$

\begin{tabular}{ccc}
\hline Cell line & Compounds & IC $_{\mathbf{5 0}}(\mu \mathrm{M})$ \\
\hline & $\mathbf{1}$ & $57.78 \pm 1.95$ \\
& $\mathbf{3}$ & $34.19 \pm 0.53$ \\
MDA-MB-231 & $\mathbf{4}^{\mathbf{b}}$ & $45.20 \pm 1.37$ \\
& $\mathbf{5}$ & $51.78 \pm 0.73$ \\
& $\mathbf{6}^{\mathbf{b}}$ & $>50$ \\
Paclitaxel $^{\mathbf{1}}$ & $8.38 \pm 0.75$ \\
\hline & $\mathbf{1}$ & $74.25 \pm 0.46$ \\
& $\mathbf{3}$ & $34.41 \pm 1.57$ \\
RD & $\mathbf{4}^{\mathbf{b}}$ & $>50$ \\
& $\mathbf{5}$ & $70.95 \pm 1.94$ \\
& $\mathbf{6}^{\mathbf{b}}$ & $29.07 \pm 3.47$ \\
& Paclitaxel $^{\text {bes }}$ & $5.73 \pm 0.27$ \\
\hline
\end{tabular}

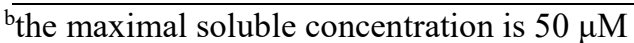



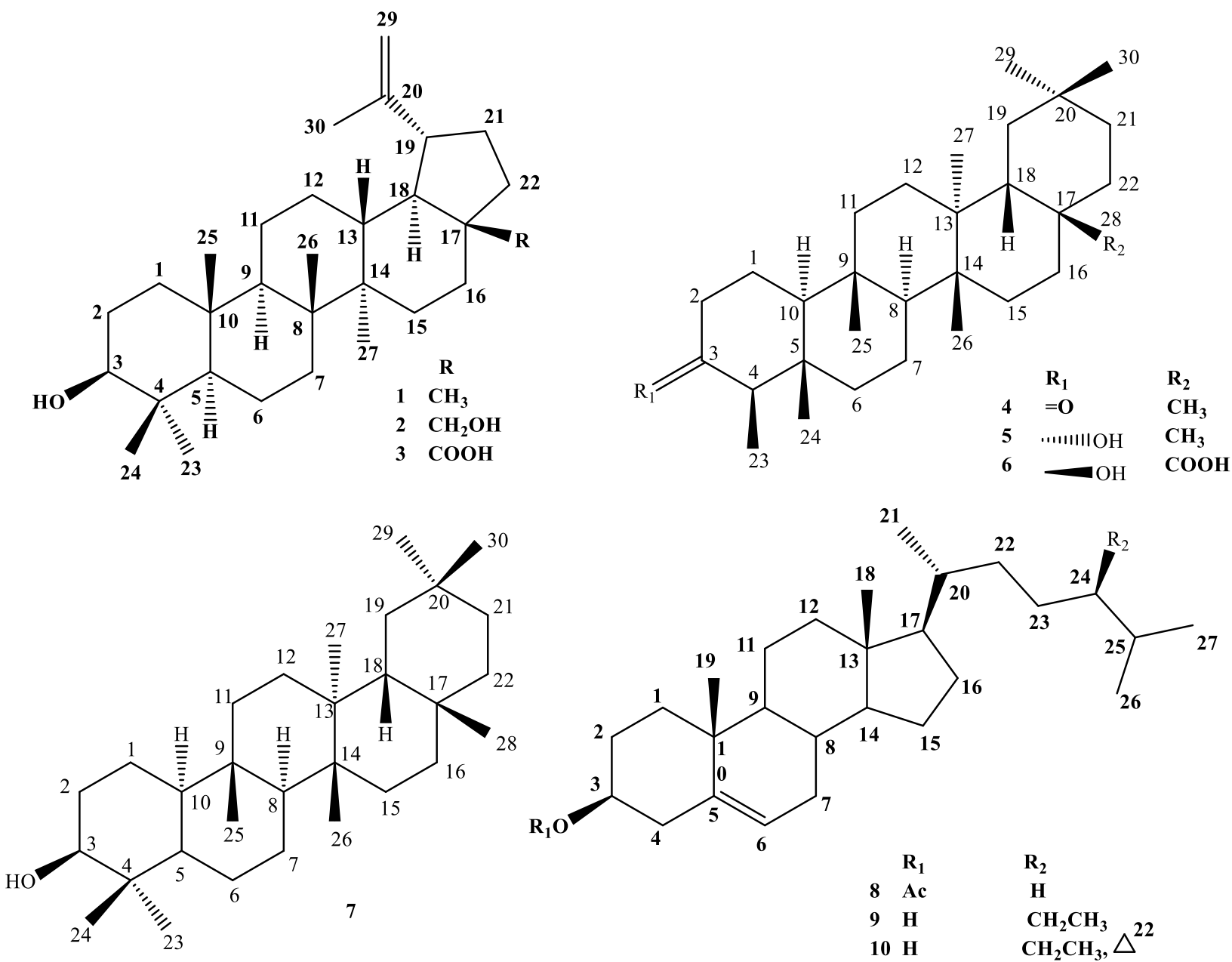

Figure 1. Chemical structures of compounds (1-10)

In conclusion, a systematic chemical investigation of Macrosolen bidoupensis Tangane \& V.S. Dang, was reported for the first time herein. Phytochemical investigation of the active extracts indicated that the triterpenoids present in this species accounted for their cytotoxic activity.

\section{Acknowledgments}

This research is funded by Vietnam National Foundation for Science and Technology Development (NAFOSTED) under grant number 104.01-2018.48.

\section{Supporting Information}

Supporting Information accompanies this paper on http://www.acgpubs.org/journal/recordsof-natural-products 


\section{ORCID}

Kieu Hung Le: 0000-0003-0964-7751

Tran Canh Nguyen: 0000-0002-3711-172X

The Anh Nguyen: 0000-0002-4405-9413

Nu Dan Phuong Nguyen: 0000-0003-0529-0169

Thi Hong Tuoi Do: 0000-0002-5445-0694

Nguyen Le Thanh Tuyen: 0000-0002-0073-7171

Van Son Dang: 0000-0001-8681-4141

Trong Duc Tran: 0000-0003-0095-6259

Nhat Minh Phan: 0000-0002-7719-9658

Trong Dat Bui: 0000-0001-8892-8396

Dinh Tri Mai: 0000-0001-8906-6003

Tan Phat Nguyen: 0000-0001-9672-2785

\section{References}

[1] S. Tagane, V. S. Dang, V. N. Nguyen, T. B. Hoang, N. Komada, J. S. Wai, A. Naiki, H. Nagamasu, H. Toyama and T. Yahara (2017). Macrosolen bidoupensis (Loranthaceae), a new species from Bidoup Nui Ba National Park, southern Vietnam, PhytoKeys. 80, 113-120.

[2] T. P. Nguyen, D. T. Mai, T. H. T. Do and N. M. Phan (2017). Flavonoids with hepatoprotective activity from the leaves of Cleome chelidonii, Nat. Prod. Commun, 12, 1061-1063.

[3] F. P. Beserra, M. Xue, M. G. L. de Azevedo, A. L. Rozza, C. H. Pellizzon and C. J. Jackson (2018). Lupeol, a pentacyclic triterpene, promotes migration, wound closure, and contractile effect in vitro: possible involvement of PI3K/Akt and p38/ERK/MAPK Pathways, Molecules 23, 2819.

[4] W.A. Matebie, W.C. Zhang, S. Zhang and G.B Xie (2019). Triterpenoids from Acokanthera schimperi in Ethiopia, Rec. Nat.Prod. 13(3), 182-188.

[5] A. Tijjani, I. G. Ndukwe and R. G. Ayo (2012). Isolation and characterization of lup-20(29)-ene-3,28diol (betulin) from the stem-bark of Adenium obesum (Apocynaceae), Trop. J. Pharm .Res. 11, 259262.

[6] S. Salimuzzaman, H. Farrukh, B. Sabira and S. S. Bina (1988). Oleanderol, A new pentacyclic triterpene from the leaves of Nerlum Oleander, J. Nat. Prod.51, 229-233.

[7] G. C. M. Salazar, G. D. F. Silva, L. P. Duarte, S. A. Vieira Filho and I. S. Lula (2000). Two epimeric friedelane triterpenes isolated from Maytenus truncata Reiss: ${ }^{1} \mathrm{H}$ and ${ }^{13} \mathrm{C}$ chemical shift assignments, Magn. Reson. Chem. 38, 977-980.

[8] M. M. Fragaa, M. Reinaa, J. G. Luis and M. L. Rodríguezb (2003). Rhoiptelenol and rhoiptelenone, two pentacyclic triterpenes from Sideritis macrostachya, Z. Naturforsch. 58c, 621-625.

9] W. K. Wilson, R. M. Sumpter, J. J. Warren, P. S. Rogers, B. Ruan and G. J. Schroepfer (1996). Analysis of unsaturated $\mathrm{C}_{27}$ sterols by nuclear magnetic resonance spectroscopy, J. Lipid Res. 37, 15291555.

[10] C. Y. Ragasa, R. F. Galian and C. C. Shen (2014). Chemical constituents of Annona muricata, Pharm. Chem. 6, 382-387.

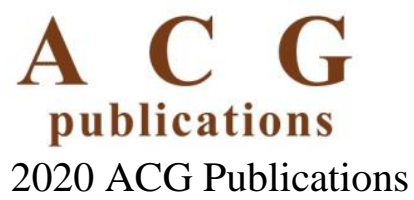

